\title{
EXPERIMENTAL STUDIES ON LAUNCH DYNAMICS OF SLANT LAUNCHED SURFACE TO AIR FLIGHT VEHICLE
}

\author{
G Chandramouli* \\ Former Programme Director, \\ Defence Research and Development Laboratory, Hyderabad, India \\ P Ravinder Reddy \\ Principal and Professor, Department of Mechanical Engineering \\ Chaitanya Bharati Institute of Technology, Hyderabad, India
}

\author{
P Laxminarayana \\ Professor, Department of Mechanical Engineering, College of Engineering (A), \\ Osmania University, Hyderabad, India \\ Mondeep Borthakur \\ Scientist, Defence Research and Development Laboratory, Hyderabad, India \\ *Corresponding Author Email: chandramoulig@yahoo.com
}

\begin{abstract}
Surface to air flight vehicles are launched at low slant angles to intercept and neutralize low flying attacking enemy aerial targets like fighter aircrafts, helicopters which are on cruise missions. These flight vehicles are generally housed in hollow launch canisters which are used for storage, transportation and launching through mobile launchers. The lateral signature of launch canister is chosen such a way that more number of canisters can be accommodated per one launcher. To accommodate the flight vehicle in launch canister, it is accordingly configured with foldable wings and fins. New designs of flight vehicle, canister and launcher system need to be verified for all the interfaces and the controllability of flight vehicle when it clears the canister. While coming out of canister at low elevation launch angles, the flight vehicle starts deviating from its intended trajectory due to the combination of gravitational force, thrust misalignments, aerodynamic forces, low initial thrust, lateral shift of centre of mass, deployment forces of wing and fin etc. To record actual launch dispersions and to remove any hidden uncertainties in new designs, a live firing with a full scale short duration flight vehicle was undertaken. A propulsion system was specifically designed to function for a small duration simulating the actual thrust time profile of that of the full scale rocket motor system for that initial duration. One short duration rocket motor system was static tested to verify the design parameters and another one was integrated with the rest of the actual flight hardware
\end{abstract}


thus realizing in to a full scale short duration flight vehicle. The geometry, length, weight and centre of mass, launch shoe interfaces etc of short duration flight vehicle was ensured as that of actual full scale flight vehicle. Actual launcher, actual canister and short duration flight vehicle were appropriately instrumented. Parameters like vibration, shock, accelerations, body rates, pressure, temperature, strain, acoustic etc. were recorded in real time during the live firing. The motion of short duration flight vehicle, its attitude, unfolding of wings, unfolding of fins etc were recorded through high speed video sensors. Variations of parameters recorded in actual dynamic conditions were compared with estimated parameters. Some useful inputs have been obtained for improving the design for low elevation launch angle missions. The effects of these improvements have been subsequently verified through simulations and full scale live flight tests.

Keywords: deployment, flight vehicle, full scale, launch canister, live firing, rocket motor, short duration.

Cite this Article: G Chandramouli, P Ravinder Reddy, P Laxminarayana and Mondeep Borthakur, Experimental Studies on Launch Dynamics of Slant Launched Surface to Air Flight Vehicle. International Journal of Mechanical Engineering and Technology. 11(5), 2020, pp. 22-33. https://iaeme.com/Home/issue/IJMET?Volume $=11 \&$ Issue $=5$

\section{INTRODUCTION}

Surface to air flight vehicles (FVs) are designed to intercept and incapacitate enemy aerial targets like fighter aircrafts, helicopters, unmanned aerial vehicles and cruising flight vehicles. The enemy targets which are in attacking cruise missions and flying at very low altitudes are the most difficult targets to be intercepted. To track and neutralize these very low altitude targets, FVs are required to be launched at low elevation angles and need to be controlled and guided immediately after launch. These FVs are generally housed in hollow launch canisters which are used for storage, transportation and launching through mobile launchers. The configuration of launch canister is designed such a way that more number of canisters can be accommodated per one launcher.

The FV under investigation is loaded into canister through a guide rail with the help of two launch shoes located on either side of centre of mass and with its four wings and four fins folded condition. For operational reasons, the FV is fitted with four jet vanes near the nozzle to create quick lateral moment. When the FV begins to travel along the guide rail of the canister, it passes through three boundary conditions with respect to guide rail. In the first condition, FV moves for a certain amount of time in the rail with both launch shoes. In the second condition, the front launch shoe of FV is out of guide rail and rear launch shoe is still inside guide rail.

In the third condition, which is called 'no control phase', both the launch shoes are out of guide rail of canister and unfolding of wings and fins start taking place. During this phase, the FV starts deviating from intended launch trajectory as a result of moments generated due to combination of the forces or misalignments like gravitation force, thrust misalignments, aerodynamic forces, low initial thrust, lateral shift of centre of mass, misalignment of jet vanes, deployment forces of wing and fin etc. For a new surface to air flight vehicle system to be designed with inclined launch feature, there is a necessity to precisely estimate or know quantitative values of these launch dispersions so that further controllability of FV is ensured. It is also essential to validate all the interface designs between canister and FV during launching under dynamic conditions 
To meet this objective, it was decided to realize a full scale short duration flight vehicle (SDFV) and launch with actual canister and launcher. A propulsion system was specifically designed to function for about $0.6 \mathrm{Sec}$ which simulates the actual thrust time profile of full scale rocket motor system for that initial duration. Three short duration rocket motor systems were realized and out of which one is static tested to verify the design parameters, second rocket motor was integrated with the rest of the actual flight hardware thus realizing a full scale short duration flight vehicle. The geometry, length, weight and centre of gravity, launch shoe interfaces etc of short duration flight vehicle was ensured as that of actual full scale flight vehicle. Actual launcher, actual canister and short duration flight vehicle were appropriately instrumented. Parameters like vibration, shock, accelerations, body rates, pressure, temperature, strain, acoustic etc. were recorded in real time during the live firing. The motion of short duration flight vehicle, its attitude, unfolding of wings, unfolding of fins etc were recorded through high speed video sensors. Variations of parameters recorded in actual dynamic conditions were compared with estimated parameters from 6 degree of freedom simulation model. Some useful inputs have been obtained for improving the design for low elevation launch angle missions. The effects of these improvements have been subsequently verified through simulations and full scale live flight tests.

\section{BACKGROUND}

Sheng-Nan Chou et al. [1] constructed mathematical model of moving flight vehicle and inclined launcher guide rail and studied variation of pitch angle, pitch rate of FV w.r.t. time of travel for rigid guideway and elastic guideway. The authors further say that more rigorous studies to be carried out to study the motion of FV in its rotation in pitch and yaw planes with practical thrust asymmetry and other data of FV.

Liu Chaoqi et al, [2] established a launch dynamics model for surface to air flight vehicle supported by four sets of circular adaptors located at three longitudinal locations in the canister instead of a launch rail and studied launch dispersions. A multi body dynamic modelling was built using ADAMS in which the flight vehicle body and canister are considered rigid, velocity of $\mathrm{FV}$ is less than $25 \mathrm{~m} / \mathrm{s}$, the aerodynamic forces, thrust misalignment, axis offset, impact of elastic vibration of vehicle etc are negligible. It was mentioned that where folded wings and fins are used in the canister, the safety against collision of adopters is required to be ensured through a robust design. It was concluded the pitch angular speed of FV increases substantially as the launch angle is decreased.

Shaik Ismail et al [3] studied tip off data using a 3 D Finite element models by considering flexibility of launcher, flight vehicle and aircraft flow fields. Results from low fidelity models, flight measured data are compared with 3D finite element model. Transients captured during rail travel are better by 3D FEM method compared to rigid body results.

Suk Young Jung and Sung Joon Yoon, [4] studied motion analysis of unfolding fin and presented an aerodynamic model of unfolding fin including damping to get realistic scenario. It is mentioned that the aerodynamic folding moment consists of static folding moment and the damping generated by the rotation motion of fin around its hinge axis. Several wind tunnel tests were carried out to deploy the fin under different wind speeds, angles of attack and angles of side slip. The fin is observed to be in its unfolding motion while its angular velocity is positive. Once the angular velocity drops below zero, the fin fails to deploy. It is found that the simulation results for unfolding fin became more accurate after including damping moment coefficients.

Knauber [5] studied data of number of solid rockets with fixed nozzles and their misalignments through number of flight and ground tests. He stated that are manufacturing mechanical tolerances, motor case distortions, nozzle cant angles as a result of pressurization, 
non-symmetrical nozzle erosion, transient gas flow phenomenon from internal ballistics, radial offset of centre of mass, static unbalance produced by propellant bore concentricity errors etc. are major sources of thrust misalignment. Variation in thrust misalignment component in pitch and yaw planes were presented with respect to time of operation. Formulae for effective thrust misalignment were presented for solid rockets under the presence of lateral shift of centre of mass and concentricity shift of nozzle w.r.t. axis of rocket motor casing. Very large thrust misalignments were observed during initial pressure rise (pressurization) due to asymmetric initiation of burning of propellant and asymmetric flow across nozzle. These forces were observed to act within $15-30 \mathrm{~ms}$ and excite the structural modes of the flight vehicle which may result in to large angular rates at the exit of launch beam. He observed that while casting the propellant, if there is a considerable shift in the bore axis of propellant with reference to the axis of motor casing, static unbalance increases with burning time, centre of mass shifts radially and higher disturbing forces are generated. The importance of alignment of flight vehicle axis and rocket motor axis is also highlighted along with the mass distribution of other modules symmetric to the longitudinal axis.

\section{PARAMETERS THAT INFLUENCE LAUNCH DISPERSIONS}

As soon as the FV comes out of canister rail, the FV is subjected to rotations in three axes and displacement in three directions within the duration in no control phase. The rotation with respect to FV's own axis (X-axis) is Roll, the rotation with respect to centre of mass in vertical plane is Pitch and the rotation of with respect to centre of mass in horizontal plane is termed Yaw. The direction of thrust force (T), centre of mass (C.M.), Gravitation force rotations in three planes acting on any typical flight vehicle are shown in Fig 1 for reference.

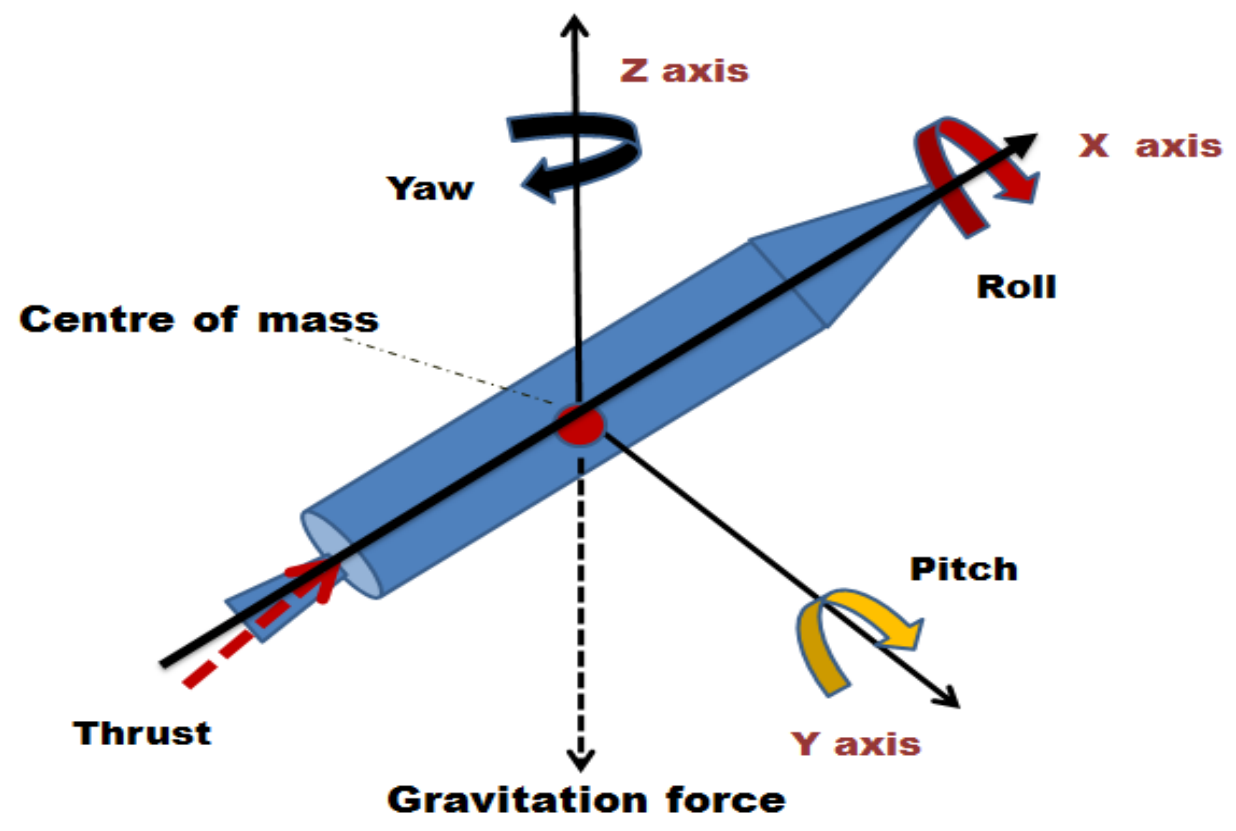

Figure 1 Roll, Pitch and Yaw rotations

The angular velocities of FV in three rotations are called Roll rate, Pitch rate and Yaw rate. Generally the pitch rate is also termed as tip off rate. The sudden ignition of propellant of rocket motor may also result in to excitation of launch canister, launch beam or flight vehicle structures producing significant changes in body rates, accelerations of FV. The deviations of these values at launch from the normal expected values in no control phase are termed as launch dispersions. 
Generally these launch dispersions are observed to depend on the variations of parameters like pitch rate, yaw rate, roll rate, forward acceleration, movement of flight vehicle in $\mathrm{X}, \mathrm{Y}, \mathrm{Z}$ directions, lateral vibrations, shock etc. These parameters are in turn may depend on variation of one or more parameters like thrust force, gravitational force, aerodynamic forces, frictional force, unfolding force of fin, unfolding force of wing, misalignment of wings, misalignment of fins, thrust misalignment, misalignment of jet vanes, mass of flight vehicle, lateral centre of mass of flight vehicle, axial location of centre of mass, location of shoes on flight vehicle, tolerances between guide rail and shoes of flight vehicle, number of launch shoes, shape of launch beam and guide rail, mass moment of inertia of flight vehicle in $\mathrm{X}, \mathrm{Y}$ and $\mathrm{Z}$ directions, rigidity of flight vehicle, rigidity of launch shoes and their connectivity with flight vehicle, rigidity of launch guide rail support structure, rigidity of launcher system, umbilical shear mechanism, launch angle in elevation etc.

Thrust misalignment [5] in turn observed to depend on nozzle misalignment, concentricity mismatch between rocket motor casing and nozzle throat, concentricity mismatch between nozzle throat and propellant inner diameter, asymmetric burning of propellant, asymmetric erosion of throat, chip of nozzle throat under the impact of igniter product ejection. Aerodynamic forces on flight vehicle depends on dynamic pressure, lift coefficients, drag coefficients, roll moment coefficients, diameter of flight vehicle, angle of attack, angle of side slip etc. However, in this no control phase, the velocity of FV is low and hence these forces can be neglected.

Mathematical modelling of all the real scenarios, boundary conditions and predicting the launch dynamics of overall system is a complicated exercise. However, assumptions are done at modelling the subsystems and systems by neglecting some non predominant parameters / conditions. Some approximations are made at macro levels to represent the overall system close to the real system. The experimental studies and correlation of results with the theoretical approximations can thus help in building up the knowledge base for future applications. From the proposed experiment, the total disturbing moment will be computed using the measured body rates and estimated moment of inertia. Similarly from estimated lateral centre of mass and measured thrust misalignment the disturbing moments expected are compared with recorded values from experiment and necessary actions required will be arrived at for design improvements.

\section{SHORT DURATION ROCKET MOTOR (SDRM) PROPULSION SYSTEM}

\subsection{Configuration of SDRM}

To facilitate validate the new interface designs of launcher, canister, Flight vehicle and to study the movement of flight vehicle after launching (before control system is initiated), there is a requirement of designing a propulsion system which will simulate thrust for the intended short duration of about $0.6 \mathrm{Sec}$. Ideally, the flight motor working for this time is best suited. But it is not feasible to constrain the actual rocket motor to work for this short duration without making changes to its overall design. Hence a SDRM propellant system has been specifically designed and manufactured to work for the intended short duration exactly simulating the internal ballistic parameters, external geometry and mass properties. The diameter, weight and centre of mass of SDRM is kept same as that of actual flight vehicle with a facility to mount folded wings, fins, launch shoes, fairing. SDRM system consists of two main parts, one is the dummy section in the front which has same diameter and can accommodate an adjustable ballast weight to simulate mass properties and has facility to mount foldable wings. The other part is a short duration propulsion motor system which is short in length, same diameter as actual rocket motor and consists of propellant grain, an 
igniter, a nozzle and a rear section with four jet vanes. The entire construction is configured keeping in view of ease of assembly.

\subsection{Design of Short Duration Rocket}

The rocket motor casing is designed with easily available alloy steel material with adequate factor of safety as per pressure vessel regulatory code. Since the time of operation of short duration rocket motor is only about 600 milliseconds (ms), motor is designed without insulation of motor casing and nozzle. The OD of the cylindrical motor is kept same as that of flight vehicle; its thickness is chosen as per the calculation of pressure vessel criteria. For the chosen duration of a burn rate of appropriate web thickness was arrived at. The length of grain required to meet the required pressure was chosen accordingly. A cylindrical grain configuration with a diameter was chosen as it is the simplest shape from casting point of view. Simulations were carried out with the design input burn rate, pressure exponent, propellant density, throat diameter, exit diameter.

\subsection{Static Testing of SDRM}

To evaluate the desired ballistic performance of SDRM, a static test has been carried out on one of the three SDRMs realized with required instrumentation. Pressure inside rocket motor, temperature on nozzle, thrust force, strain on nozzle, vibration on the casing etc parameters were measured during static test. A comparison is made between the parameters recorded in the static test of SDRM with respect to the estimated parameters of full scale motor system. After ensuring satisfactory performance through static test, another SDRM (which was casted with propellant along that of static tested SDRM), is integrated with other actual flight hardware consisting of avionics, telemetry system, folded fins, folded wings, jet vanes etc in to a short duration flight vehicle (SDFV). The performance of SDFV is verified for its electrical performance with the help of ground computer checkout system. SDFV is then loaded in to the canister for the scheduled experimental test.

\section{SHORT DURATION FLIGHT VEHICLE (SDFV) EXPERIMENT}

\subsection{System Studies}

System studies are carried out with Six Degree of Freedom (6-DOF) simulation model integrating the propulsion data and using the mass, centre of mass, moment of inertia data of flight vehicle. Simulation studies were carried out with different launch elevation angles and an elevation launch angle of $20^{\circ}$ is selected for the experiment.

\subsection{Measurements Planned for Short duration Flight Vehicle Test}

Pressure measurement inside the rocket motor at head end, strain measurement at some selected locations on rocket motor and air frame of flight vehicle, acoustic pressure measurement close to launch canister etc. Various events during movement of FV to be captured starting from ignition of rocket motor, clearance of FV from launch canister, deployment of wings, fins etc through two high speed cameras to be placed perpendicular to the launch azimuth axis of the short duration flight vehicle.

\subsection{Live Firing of Short duration Flight Vehicle}

A rocket motor system with burn duration of $0.6 \mathrm{Sec}$ was designed with thrust-time profile similar to the full scale flight motor. Three short burn rocket motor systems were realized, one of them was static tested with appropriate instrumentation. After satisfactory performance recorded through static test, the second short burn rocket motor system was integrated with a full scale flight hardware simulating the mass, centre of gravity. The third short burn rocket 
motor was kept as a standby. The experimental flight vehicle also consists of actual flight hardware with spring loaded folded fins, spring loaded folded wings, launch shoes, jet vanes for thrust vector control, control sensors, on board power supply system, on board computer system. An on board telemetry unit was also integrated with the flight vehicle to transmit the measurements in real time as it moves in the canister and out of the canister. A live firing was conducted with short duration flight vehicle using actual canister and actual launcher thus simulating actual flight test conditions.

\section{RESULTS AND ANALYSIS OF SDRM TEST AND SDFV TESTS}

The performance of short duration rocket motor recorded in static test is shown in Fig 2. The thrust versus time profile recorded very closely matches with the design profile. As seen in Fig 3, the short duration rocket motor of flight vehicle burns for about $668 \mathrm{~ms}$ within specified tolerance range mentioned in Table 1. The total rise time is recorded to be about 50 $\mathrm{ms}$ which is close to prediction. The pressure versus time profile of short duration rocket motor and short duration flight vehicle shown in Fig 2 very closely matches and thus could facilitate precise conduct of live firing. Table 2 indicate deviation of mass properties of SDFV with SDRM motor and actual flight vehicle configuration with full duration rocket motor. During no control phase, significant angular body rates are recorded in pitch plane in SDFV test (Fig 4) when compared to predicted/estimated value of $18 \mathrm{deg} / \mathrm{sec}$. Similarly significant body rates are recorded in Yaw plane (Fig 5) compared to the estimated values of $10 \mathrm{deg} / \mathrm{sec}$. It is seen that the front launch shoe of the FV comes out of guide rail in about $220 \mathrm{~ms}$ time compared to estimate time of $240 \mathrm{~ms}$. Similarly the rear launch shoe comes out of guide rail in about $350 \mathrm{~ms}$ compared to predicted time range of $380 \mathrm{~ms}$.

When the front launch shoe of the FV is just about to come out of the rail, the lateral moments acting on the FV are contained by the guide rail at two points. As soon as the front launch shoe is just out of the guide rail, large lateral disturbances/moments are seen. These higher moments are due to the sudden release of reaction force at the front launch shoe. The FV now starts experiencing lateral moments with respect to only rear shoe as a cantilever overhang with thrust force acting on the FV and gravitation force acting at the centre of mass. The small oscillations are observed as the FV starts movement with the rear shoe alone in the guide rail as it continue to keep moving forward. These forward and lateral movements of flight vehicle are measured by various sensors mounted on the FV. The total disturbing moments observed in SDFV flight test is calculated from the estimated mass moment of inertia at that particular time using the extracted angular acceleration from the body rates observed in the flight.

Table 1 SDRM and SDFV test results

\begin{tabular}{|c|c|c|c|}
\hline Parameter & Specification & $\begin{array}{c}\text { SDRM } \\
\text { Static test }\end{array}$ & $\begin{array}{c}\text { SDFV } \\
\text { Test }\end{array}$ \\
\hline Duration $(\mathrm{ms})$ & $600_{-50}^{+120}$ & 637 & 668 \\
\hline
\end{tabular}


G Chandramouli, P Ravinder Reddy, P Laxminarayana and Mondeep Borthakur

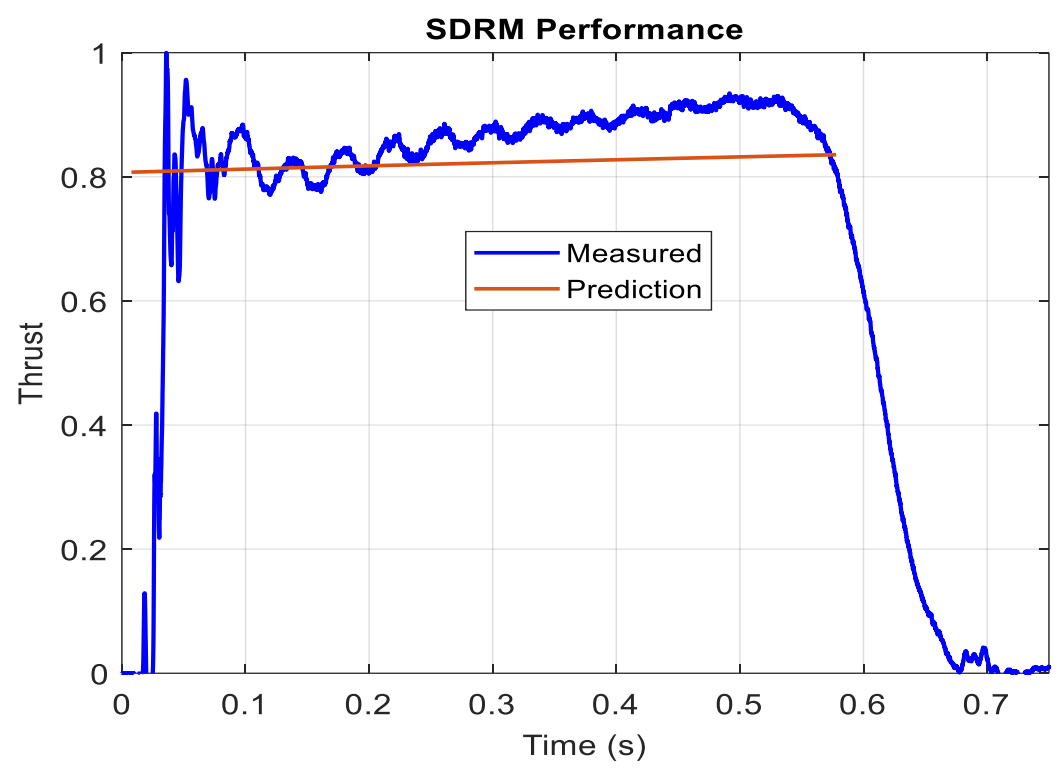

Figure 2 Thrust Vs Time SDRM and Prediction

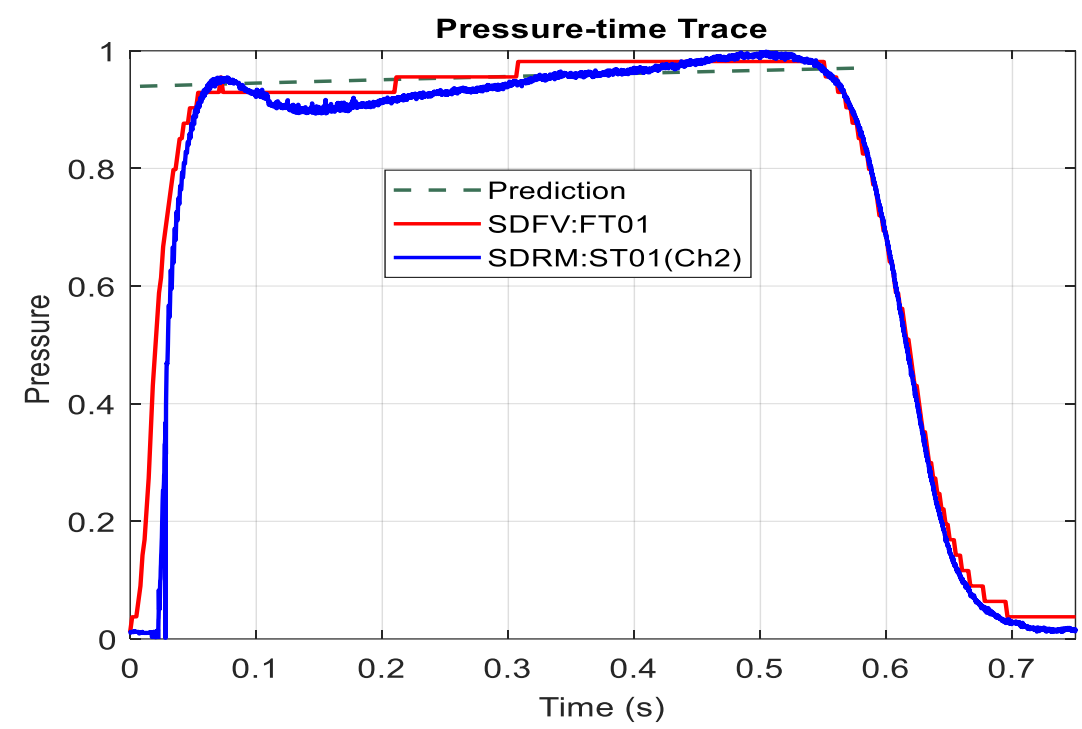

Figure 3 Pressure Vs time SDRM, Prediction, SDFV tests

Table 2 Deviation of mass properties of SDFV w.r.t actual FV

\begin{tabular}{|c|c|c|c|}
\hline \multirow{2}{*}{ Time (Sec) } & \multicolumn{3}{|c|}{ Parameter: } \\
& ( Percentage deviation of SDFV w.r.t actual FV) \\
\hline Time (s) & Xcm (mm) & Ycm (mm) & Zcm (mm) \\
\hline $\mathrm{T}_{0}$ & 0.21 & 0.39 & 0.31 \\
\hline $\mathrm{T}_{0}+0.6$ & 0.65 & 0.41 & 0.35 \\
\hline Time (s) & Ixx (kg-m2) & Iyy (kg-m2) & Izz (kg-m2) \\
\hline $\mathrm{T}_{0}$ & 9.9 & 3.4 & 3.4 \\
\hline $\mathrm{T}_{0}+0.6$ & 9.9 & 6.8 & 6.8 \\
\hline
\end{tabular}


Experimental Studies on Launch Dynamics of Slant Launched Surface to Air Flight Vehicle

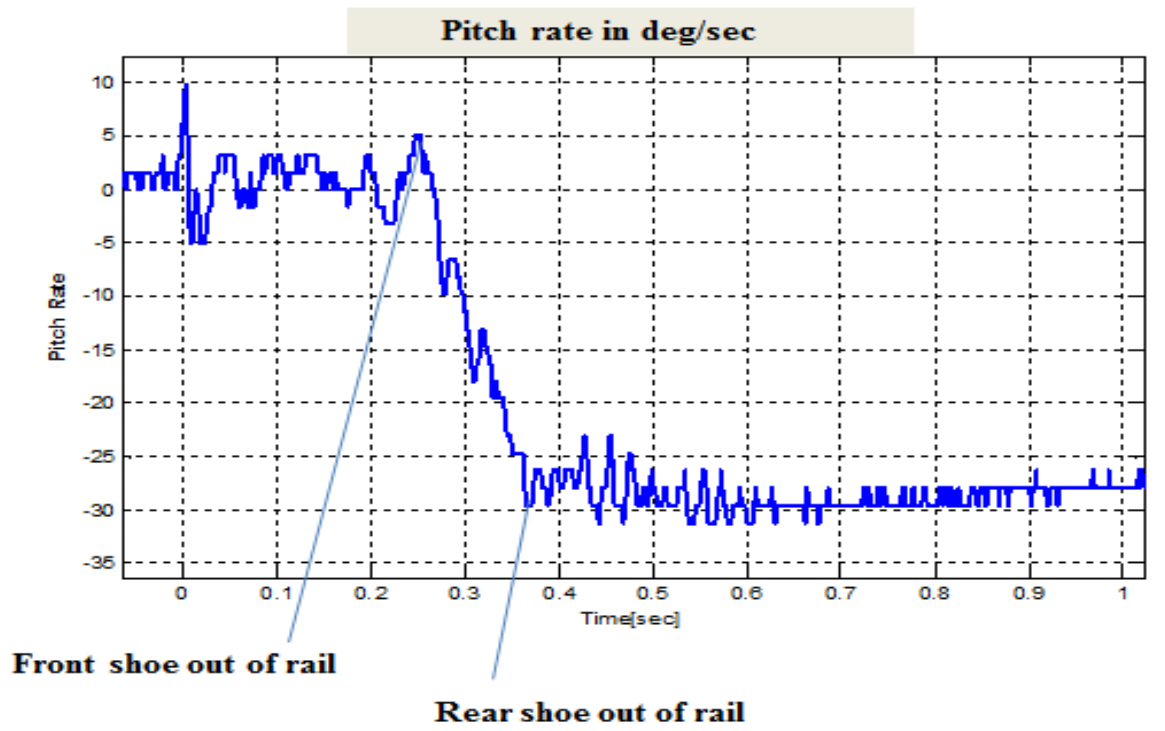

Figure 4 Pitch rate recorded in SDFV test

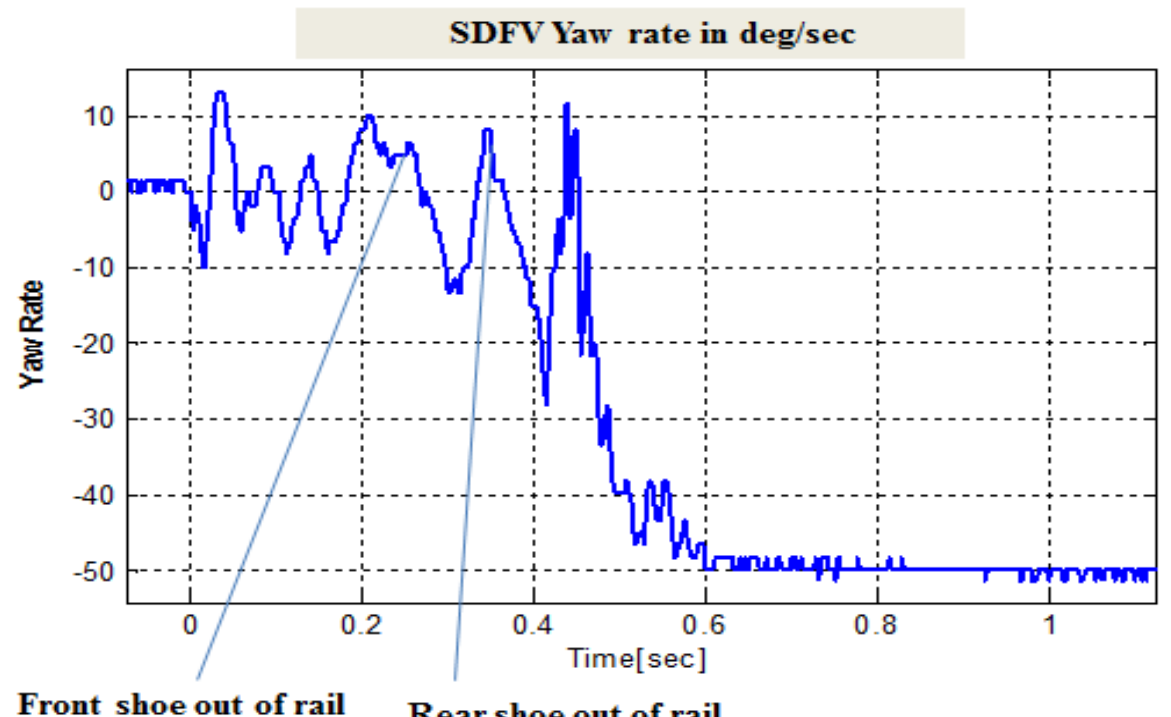

Front shoe out of rail Rear shoe out of rail

Figure 5 Yaw rate Vs time SDFV test

Forward acceleration profile Vs time

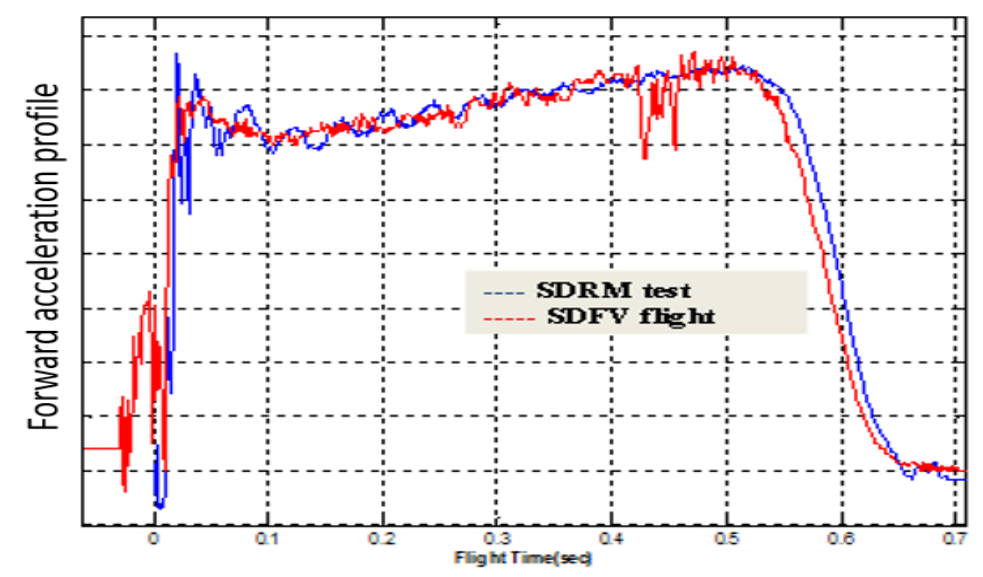

Figure 6 Forward Acceleration SDFV test \& SDRM test 


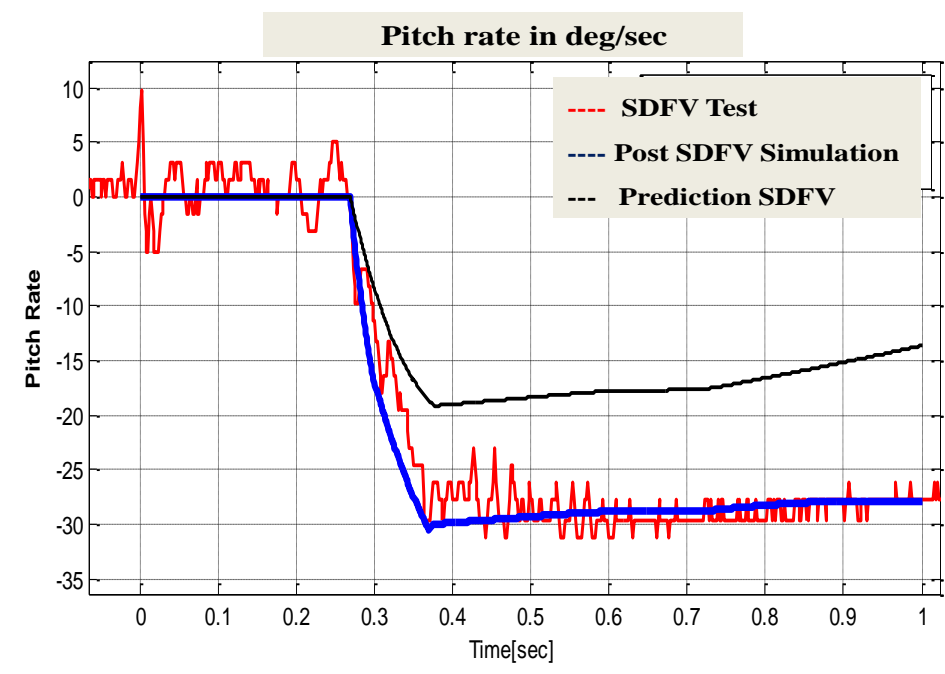

Figure 7 Comparison of Pitch rate SDFV, Post SDFV Simulation, Prediction

Angular accelerations in pitch and yaw are derived from the pitch and yaw rates measured in the flight during free flight phase. Similarly the angular acceleration in roll direction is calculated from the measured roll rate. The disturbance moment as experienced in flight is computed considering predicted moment of inertia. For the chosen elevation launch angle, the estimated pitch rate as per the simulation is $18 \mathrm{deg} / \mathrm{sec}$. However, in the experiment, it is observed to be about $30 \mathrm{deg} / \mathrm{sec}$. Similarly, the yaw rate is estimated to be about $10 \mathrm{deg} / \mathrm{sec}$, however it reaches to about $50 \mathrm{deg} / \mathrm{sec}$ at $0.40 \mathrm{Sec}$ in no control phase. It is observed that the launch disturbing moments calculated from flight measured body rates and accelerations show that they are three to five times higher than estimated values. Possibility of large variations of different sources like moment due to jet vanes, moment due to lateral shift in centre of mass, overall thrust misalignment etc were investigated with respect to pre-flight estimated / inspection values.

While the flight vehicle is moving forward in guide rail of canister, the clearance between launch shoe and rail is observed to be about 900 microns in yaw and about 640 microns in pitch direction against the specified limit of 500 microns. Time to clear first and second launch shoe are close to predictions. Forward acceleration values recorded are close to predictions. Flight vehicle is observed to be rolling heavily after booster burn out time confirming large lateral disturbing moments. Oscillations are observed at the beginning of opening of fin, which is reduced after full opening. Deflection of about 2.0 degrees may be required at for any two jet vanes to produce the observed disturbing torque. No significant structural vibrations could be noticed due to the firing of rocket motor. The system is observed to be free from acoustic initiated excitation. During no control phase, the forces and moments as a result of unfolding of wings and fins do not add significant body rates and accelerations. The time for deployment of wings and fins are closely matching with the design specifications. The overall clearances designed between launch canister, folded wings and fins are found adequate. Location of metallic guide in canister and spring force of wings and fins are adequate not to create any damages to the folded wings and fins during the travel of flight vehicle in the canister.

It is observed that for low elevation launches, two parameters are of utmost importance which ultimately may result in to large launch dispersions of FV. The first parameter is the moment created due to overall thrust misalignment and lateral shift of centre of mass. The overall thrust misalignment to include misalignment due to jet vanes also. The second 
parameter is the moment generated due to gravitation force with respect to axial location of centre of mass.

\subsection{Some Points for Improvement}

Assembly of jet vanes with rocket motor system need to be carried out using precisely adjustable fixture. Methods need to be evolved for measurement of overall thrust misalignment in the presence of four jet vanes. Suggested to experimentally measure lateral shift of centre of mass for the full scale flight vehicle and compare with the predicted data from the solid model. Similarly, mass moment of inertia of flight vehicle also needs to be measured to verify with the estimated value. An experimental set up explained similar to the one described in [6] can be set up and measure mass moment of inertia for the flight vehicle. For better controllability, starting of control phase of flight vehicle can be slightly advanced and minimum launch elevation angle can be finalized accordingly.

\section{CONCLUSIONS}

The performance of short duration rocket motor propulsion system closely matches with the actual thrust verses time profiles of full scale motor. The short duration flight vehicle test could facilitate recording the actual launch disturbances that are encountered as that of full scale flight vehicle. The body rates and accelerations recorded for the flight vehicle are observed to be two to four times higher than the estimated values as per simulations. The reason most likely could be due to some combination of the parameters like thrust misalignment, lateral shift of mass, high disturbing moment due to jet vanes and their variance particularly when the flight vehicle comes out of front launch shoe. Appropriate methods were recommended to evolve for precise measurement of lateral mass moment of inertia, lateral shift of centre of mass and overall thrust misalignment in the presence of jet vanes. Some of the recommendations suggested after the short duration flight test were implemented in full scale flight tests and improvements in designs could be verified.

\section{ACKNOWLEDGEMENTS}

The authors are thankful to Director, Defence Research and Development Laboratory (DRDL), Hyderabad and Project Director for interactions, review and valuable suggestions. The authors are also grateful to Group Director, Propulsion and team for providing required technical inputs and suggestions for the experiment.

\section{REFERENCES}

[1] Sheng-Nan Chou, Fu-Ping Cheng, Chiung-Shiann Huang, "Tip-off effect analysis of a vehicle moving along an inclined guideway by considering dynamic interactions, "Journal of the Chinese Institute of Engineers, Vol 36, No 2, pp 164-172. 2013.

[2] Liu Chaoqui, Wen LiHua, He Jiangjun, Liu Yuxiang, "Research on Launch Dynamics Modeling and Simulating for Surface-to-Air missile Supported by Adapter," MATEC Web of Conferences 175, 03038, IFCAE-IOT, 2018

[3] Shaik Ismail, Jain, P.C., Anjaneyulu, P.S.R., "Effect of flexibility and aircraft flow field on rail launch simulation of missile," Journal of Aerospace Sciences and Technologies, Vol. 68, No 2, May, pp 81-88. 2016.

[4] Suk Young Jung, Sung Joon Yoon, “Aerodynamic Modeling of Folded Fin for Unfolding Motion Simulation, "Journal of Spacecrafts and Rockets, Vol 47, No 3, May, pp 413-418, 2010 . 
G Chandramouli, P Ravinder Reddy, P Laxminarayana and Mondeep Borthakur

[5] Knauber, R.N., "Thrust Misalignments of Fixed-Nozzle Solid Rocket Motors," Journal of Spacecraft and Rockets, Vol. 33, No. 6, November, pp 794-799. 1996.

[6] Michael Koken, "The Experimental Determination of Moment of Inertia of a Model Aeroplane," Honours Research Projects, 585, The Dr Gary B and Pamela S Williams Honours College, The University of Akron, Ohio, USA. 2017. 